\author{
И. Мендоза \\ Зальиябургский университет имени Париса Лодрона \\ (Зальбург, Австрия) \\ imke.mendoza@sbg.ac.at
}

\title{
МАРКИРОВАНИЕ ОБЬЕКТОВ ОТНОСИТЕЛЬНЫХ ПРИДАТОЧНЫХ ПРЕДЛОЖЕНИЙ В СЛАВЯНСКИХ ЯЗЫКАХ
}

В данной статье анализируется употребление несклоняемых относительных маркеров (рус. что, польск. со и т. п.) при релятивизации прямого объекта. Функция прямого объекта в иерархии доступности, предложенной Keenan-oм \& Comrie в 1977 году, представлена как нечленимая, но при подробном анализе отдельных языков она представляется более многоплановой. Это становится особенно очевидно в том случае, если рассматривается релятивизация с использованием несклоняемого относительного маркера. На выбор стратегии релятивизации здесь воздействуют различные факторы такие, как (семантическая) одушевленность, тождество синтаксических функций вершины и релятивизируемой позиции (case matching), а также парадигматическое соотношение объектных падежей вершины. Предлагается интерпретация результатов в рамках теории дифференцированного маркирования объектов и грамматической одушевленности.

Ключевые слова: синтаксис, относительное предложение, маркирование объектов.

\section{1. Введение}

Во многих языках анализ маркирования прямого дополнения доставляет лингвисту немало сложностей. Это касается не только именных объектов, но и таких, которые являются релятивизируемым элементом относительного придаточного.

В настоящей статье рассматривается один тип стратегии, используемый для релятивизации объектов, а именно употребление так называемых относительных частиц ${ }^{1}$. Термином «относительная частица» обозначаются несклоняемые слова такие, как рус. что, польск. со, чешск. со и т.п., которые могут вводить относительные придаточные предложения, ср. (1):

\footnotetext{
${ }^{1}$ Hем. Relativpartikel, см. [Kurzová 1981]; [Mendoza 2019: 6].
} 
(1) Та самая книга, что ты мне подарил, «Корни снов». [Е. Чижов. Перевод с подстрочника, 2012; НКРЯ]

Во многих языках относительная частица может сопровождаться резумптивным местоимением, которое служит показателем синтаксической функции релятивизируемого элемента. Ср. следующий пример из польского языка, где местоимение gо маркирует позицию прямого дополнения:

(2) To jest ten, co go wczoraj puścili z aresztu. [Topolińska 1984: 345]

'Это тот, [co go] вчера выпустили из-под ареста.'

Следуя за позицией [Murelli 2011: 145-148], мы считаем, что употребление относительной частицы вместе с резумптивным местоимением, с одной стороны, и употребление частицы без местоимения, с другой, представляет собой разные стратегии. Первую мы называем «декумуляционной стратегией» [англ. decumulation, Murelli 2011: 218], а последнюю - «простой стратегией».

В дальнейшем проводится сравнительный анализ применения этих стратегий в славянских языках и приводятся факторы, влияющие на выбор подходящей стратегии. Мы не останавливаемся на нестандартных разновидностях и рассматриваем только стандартные языки.

\section{2. Относительные частицы и иерархия доступности}

Одним из самых важных инструментов для анализа относительных предложений является иерархия доступности, которая сопоставляет разные синтаксические позиции по их способности выступать в качестве релятивизируемой позиции.

Классическая иерархия, предложенная Комри и Кинэном [Keenan, Comrie 1977]; [Comrie, Keenan 1979] имеет следующий вид:

$$
\mathrm{SU} \quad>\mathrm{DO}>\mathrm{IO}>\mathrm{OBL}>\quad \mathrm{GEN}>\mathrm{OCOMP}^{2}
$$

Чем выше данная функция расположена в иерархии, тем больше она доступна релятивизации. Подлежащее (S), которое занимает самое высокое положение в иерархии, способно к релятивизации больше всех остальных позиций. Оно доступно релятивизации в каждом языке, в котором употребляются относительные придаточные предложения. На самой низкой ступени иерархии оказывается основание для сравнения (ОСОМР); оно поддается релятивизации только в немногих языках.

$\mathrm{C}$ помощью иерархии доступности можно также описать стратегии, используемые для релятивизации внутри одного языка. Данная стратегия может занимать любой фрагмент в иерархии доступности, важно только, чтобы сегмент оказался непрерывным.

Относительные частицы обнаруживаются во многих языках Европы. Стратегия с использованием частицы без резумптивного местоимения типична для позиций

${ }^{2} \mathrm{SU}=$ subject, $\mathrm{DO}=$ direct object, $\mathrm{IO}=$ indirect object, $\mathrm{OBL}=$ major oblique case $\mathrm{NP}, \mathrm{GEN}=$ genitive or possessor, OCOMP $=$ object of comparison. 
подлежащего и прямого объекта, в то время как сфера употребления декумулияционной стратегии протягивается от прямого дополнения до позиции основания для сравнения и редко позволяет релятивизировать подлежащее [Kennan \& Comrie 1977, 92]; [Murelli 2011, 216]. ${ }^{3}$

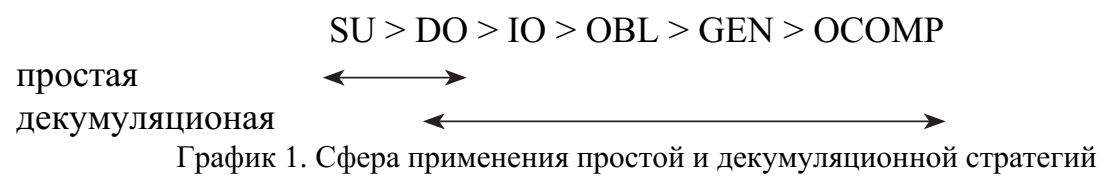

Как видно из графика 1, сферы применения простой и декумуляционной стратегий накладываются в позиции прямого объекта, в связи с тем, что эта позиция допускает обе стратегии. В классической модели она изображается как нечленимая позиция, но как будет показано ниже, она требует более дифференцированного подхода.

\section{3. Несклоняемые маркеры в функции прямого дополнения в славянских языках}

В славянских языках относительные частицы сосуществуют рядом со склоняемыми относительными местоимениями типа рус. который. В сравнении с последним относительные частицы считаются более разговорными. ${ }^{4}$

\section{1. Восточнославянские языки}

Употребление относительных частиц в восточнославянских языках до некоторой степени зависит от одушевленности объекта. ${ }^{5}$

В русском языке используется только простая стратегия. В кодифицированном русском языке неизменямое что употребляется чаще всего при неодушевленной вершине ${ }^{6}$ но в принципе такая стратегия возможна и при одушевленных объектах, в частности, в более разговорном стиле [Холодилова 2014, п. 5.3]. В примере (1), приведенном выше, релятивизируемый объект является неодушевленным, а в примере (3) указывает на одушевленный объект:

(3) не жаль таких вот или немного постарше парнишек, что тысячами бросают в бой $[\ldots]$ ? [В. Быков, 2001; НКРЯ]

3 Употребление резумптивного местоимения при релятивизации подлежащего можно встречать в разговорных разновидностях некоторых славянских языков, ср. примеры в [Mendoza 2019].

${ }^{4}$ Разговорная или даже нестандартная окраска относительных частиц является общеевропейской тенденцией [cp. Murelli 2011].

${ }^{5}$ Важно отметить, что здесь имеется в виду семантическая одушевленность, а не грамматическая.

${ }^{6}$ В [Виноградов, Истрина 1954: 274-275] употребление относительной частицы при одушевленном объекте эксплицитно запрещается. В [АГ 80: 524] о таком ограничении речи не идёт, но во всех примерах цитаты содержат неодушевленные вершины. 
Кодифицированный белорусский язык похож на русский: резумптивное местоимение не используется, и относительная частица што лицензирована прежде всего при неодушевленной вершине. ${ }^{7}$

В разговорных разновидностях таких ограничений нет. Вершины могут быть одушевленными, а рядом с относительной частицей может выступать резумптивное местоимение. В примере (4) одушевленный объект релятивизируется с помощью резумптивного местоимения яго, а в (5) - без него:

(4) Эге ж, той самы выжсал, што пан любіўяго браць на паляванне [С. Василёнак; Атрахович 1966, 609]

'Это вот этот выжлец, [што] барин с удовольствием [яго] брал с собой на охоту.'

(5) У нас ходзіць за гумном конь, ито салдаты кінулі некалькі дзён таму назад. [K. Čorny; Atraxovič 1966, 608]

'У нас за гумном ходит конь, [што] солдаты оставили несколько дней назад.'

Украинский язык, вероятнее всего, самый толерантный из восточнославянских языков. Здесь возможны и неодушевленные, и одушевленные вершины, при этом резумптивное местоимение может присутствовать или отсутствовать. В следующем примере одушевленный объект релятивизируется с помощью декумуляционной стратегии. Судя по высказываниям носителей языка, пример приемлем и без местоимения його:

(6) я зустрівся з земляком, щуо його я давно не бачив. [Danylenko 2014, 183]

'Я встретился с земляком, [щ⿻ його] я давно не видел.'

Отметим, что оценить ситуацию в белорусском и украинском языках довольно трудно по причине недостаточной изученности данного вопроса.

\section{2. Западославянские языки}

Ситуация в западнославянских языках является более сложной, чем в восточнославянских. Декумуляционная и простая стратегии представляют собой варианты, употребление которых обусловлено разными факторами.

Чешский и польский языки различают одушевленные и неодушевленные объекты. Одушевленные вершины предпочитают наличие резумптивного местоимения, тогда как неодушевленные вершины в принципе допускают оба варианта ${ }^{8}$. Следующие примеры из чешского языка иллюстрируют употребление простого

${ }^{7}$ Cр. [Акимову 1964] и [Danylenko 2014] об относительных предложениях в белорусском и украинском языках.

${ }^{8}$ Согласно [Fried 2010], одним из важных факторов при выборе подходящей стратегии для релятивизации неодушевленных объектов в чешском языке является тип относительного предложения. Так называемые «детерминативные» (determinative) относительные предложения склонны к простой стратегии, а «недетерминативные» (non-determinative) придаточные больше всего реализуют декумуляционную стратегию. Оппозиция у Фрид детермиативных и недетерминативных 
маркера для релятивизации неодушевленного объекта (7) и наличие декумуляционной стратегии при одушевленной вершине (8):

(7) Asi jste špatně rozuměl dopisu, co Vám poslali [Fried 2010, 21] 'Вы, наверное, не правильно поняли письмо, [со] Вам послали.'

(8) To je ten chlap, co ho viděli v tramvaji. [Toman 1998: 31] 'Это тот парень [со hо] они видели в трамвае.'

В польском языке наблюдается воздействие дополнительных факторов. Язык, по всей вероятности, различает объекты, обозначающие людей, от объектов, обозначающих животных. Последние допускают опущение резумптивного местоимения легче, чем первые. Итак, в примере (9) стратегия с маркером без местоимения допустима, вследствие того что референтом является собака, тогда как в (10) опустить местоимение невозможно:

(9) [О собаке $]$

A to nie jest ten co my widziałyśmy? [SPOKES; Guz 2017: 122]

'А это не тот [со] мы видели?'

(10) *ta dziewczyna, co zaprosiłeś do domu. [Guz 2017: 99]

'та девушка, [со] ты пригласил домой.'

Еще одним критерием, оказывающим влияние на выбор стратегии, является формальное отношение между вершиной и релятивизируемой позицией, а именно так называемое «case matching»". Совпадение синтаксических функций вершины и релятивизируемой позиции облегчает опущение резумптивного местоимения. Это становится видно при сопоставлении примеров (11) и (12). С точки зрения кодифицированного языка, пример (11) из разговорного корпуса SPOKES не совсем удачен. Здесь вершина стоит в винительном падеже, а релятивизируемый элемент имеет функцию родительного при отрицании ${ }^{10}$. Если же мы согласуем функции в главном и придаточном предложениях, то пример становится безупречным [Guz 2017: 107-108]:

(11) (о компьютерной игре)

może rozbrajaj najpierw te, co nie widać [SPOKES; Guz 2017: 107]

'может быть, сначала разряди те, [со] не видны'

(12) może nie rozbrajaj tych co nie widać [Modified; Guz 2017, 108]

'может быть, не разряжай те, [со] не видны.'

В словацком языке к семантическим критериям присоединяются морфологические. В результате получается довольно сложная картина. Относительная частица с̌о без резумптивного местоимения употребляется в следующих случаях: при релятивизации неодушевленных объектов, при одушевленных объектах женского рода,

придаточных является примерным эквивалентом оппозиции рестриктивынх и нерестриктивных относительных предложений.

9 Об этом термином и его синонимах см. [Murelli 2011: 217, 436].

10 То есть, при употреблении склоняемого маркера, такого как który, мы должны бы употребить форму родительного падежа których. 
не обозначающих людей, и при вершинах, у которых совпадают формы именительного и винительного падежа. Во всех иных случаях декумуляционная стратегия обязательна.

Примеры (13) и (14) показывают употребление относительной частицы без резумптивного местоимения при вершине, у которой формы именительного и винительного падежа идентичны (13), и при объекте женского рода, не обозначающего человека (14):

(13) Ženy ${ }^{11}$, čo sme cestou stretali, mali tváre zahalené závojom. [Darovec 1985: 119] 'Лица у женщин, [со] мы встретили, были завуалированы.'

(14) Ukázal mi rybu, čo včera chytil. [Darovec 1985: 119]

'Он мне показал рыбу, [со] поймал вчера.'

В (15) использование резумптивного местоимения обязательно, так как форма винительного падежа отличается от именительного:

(15) To bol ten pán ${ }^{12}$, čo sme ho nechali na ulici. [Jašík; Darovec 1985, 119]

'Это был тот человек, [со hо] мы оставили на улице.'

Воздействие морфологических факторов еще ярче проявляется в лужицких языках. В кодифицированном верхнелужицком языке относительная частица kiž употребляется только при вершинах, у которых формы винительного и родительного падежа не совпадают. Это можно проиллюстрировать следующими примерами:

znaju žonu ${ }^{13}$, kiž widźiš [Bartels, Spieß 2012: 229]

'я знаю женщин [kiž] ты видишь.'

znaju *muža ${ }^{14}, k i z ̌$ widźiš [Bartels, Spieß 2012: 229]

'я знаю мужчину, [со] ты видишь.'

Употребление резумптивного местоимения в кодифицированной разновидности языка невозможно. Разговорные стили, однако, являются более свободными в его использовании. Во-первых, в них не действует ограничение на существительные, у которых форма родительного и винительного падежа различна (18). Во-вторых, они разрешают употребление резумптивного местоимения, как показано в примере (19):

(18) Ja znajem towo muža, kiž sym ja čora widźał. [Bartels, Spieß 2012: 229]

'Я знаю того мужчину, [kiž] я видел вчера.'

(19) Je to kniha, kiž sym ju wčera kupił/. [Polański 1967, 80]

'Это кинга, [kiž ju] я вчера купил.'

В нижнелужицком языке ситуация является похожей на верхнелужицкий. Относительная частица kenž только релятивизирует объекты, вершины которых

11 Žony им. и вин. п. мн. ч.

$12 P a ́ n=$ им. п. ед. ч., pána = род. и вин. п. ед. ч.

${ }_{13}$ Вин. п. ед. ч. žоnи $\neq$ род. п. ед. ч. žоny.

${ }^{14} M u z ̌ a=$ род. и вин. п. ед. ч. 
проявляют совпадение именительного и винительного падежей [cp. Bartels, Spieß 2012]:

(20) znajom muže/žeńske ${ }^{15}$, kenž wiźiš [Bartels, Spieß 2012: 229]

'я знаю мужчин/женщин [kenž] ты видишь'

(21) znajom *muža/* žeńsku ${ }^{16}$, kenž wiźiš '[Bartels, Spieß 2012: 229]

'я знаю мужчину/женщину [kenž] ты видишь'

К тому же, частицу kenž нельзя употребить рядом с резумптивным местоимением. Кроме kenž , в нижнелужицком существует еще пара относительных частиц, а именно: $a k(o)$ и соž. Первая используется преимущественно в разговорной речи, а последняя является нестандартной. Оба маркера позволяют реализовать декумулянционую стратегию. Объекты с синкретизмом форм винительного и именительного падежа можно релятивизировать с помощью обеих стратегий (22), а такие объекты, у которых винительный падеж тождественен родительному, требуют наличия резумптивного местоимения (23):

(22) Kupijom sebje knighy ${ }^{17}$, ako sy (je) cora cytała. [Bartels, Spieß 2012: 232]

'Я куплю книгу, [ako (je)] ты читала вчера.'

(23) To jo ten ptašk, ako som se jogo kupił. ${ }^{18}$ [Bartels, Spieß 2012: 232]

'Это птичка, [ako jogo] я купил себе.'

\section{3. Южнославянские языки}

Из южнославянских языков релятивизируемые объекты дифференцирует только сербохорватский язык. ${ }^{19}$

Сербохорватский язык отличает одушевленные от неодушевленных вершин. Неодушевленная вершина в приципе допускает обе стратегии (24), в то время как одушевленный объект требует резумптивного местоимения (25) [Kordić 1999: 145146]; [Bošković 2009]:

(24) Taj brod što su ( $\mathrm{ga}$ ) kupili [Bošković 2009: 83]

'тот корабль [što (ga)] они купили'

(25) čovjek što ga je sreo [Bošković 2009, 82]

'человек [što ga] он встретил.'

15 Muže, žeńske = им. и вин. п. мн. ч.

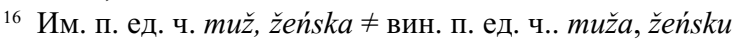

17 Knigty (plurale tantum) = им. и вин. п. мн. ч.

18 Ptaška = род. и вин. п. ед. ч.

19 Болгарский язык позволяет и декумуляционную и простую стратегии, несмотря на семантические, морофлогические и синтакситеческие признаки объекта. ср. [см. Rudin 2013]; [Krapova 2010]; [Bužarovska 2009] и др. В македонском языке для релятивизации прямого объекта используется только декумуляционная стратегия, сp. [Shagal 2016]; [Bužarovska 2009] и др. 


\section{4. Заключение}

Прежде чем говорить о полученных результатах, следует отметить, что их надо считать лишь предварительными, по причине того, что мы пока не располагаем надежными данными в достаточном количестве обо всех славянских, особенно о малоизученных, языках таких, как белорусский, украинский и словацкий.

Из анализа следует, что на выбор подходящей стратегии оказывают влияние семантические, синтаксические и морфологические факторы.

На семантическом уровне значительную роль играет одушевленность референта. Неодушевленные вершины относительного предложения позволяют использовать обе стратегии, а одушевленные объекты предпочитают маркирование с помощью резумптивного местоимения. Этот фактор действует в русском, белорусском, чешском и польском языках. Кроме того, польский язык отличает вершины, которые отсылают к животным, от тех, которые обозначают людей. При употреблении последних опущение резумптивного местоимения оказывается еще более трудным, чем при употреблении первых.

Влияние синтаксического фактора case matching проявляется в том, что совпадение синтаксических функций вершины и релятивизируемой позиции облегчает опущение резумптивного местоимения. Он обнаруживается в польском языке и, вероятно, в нижнелужицком [cp. Bartels, Spieß 2012: 299].

В словацком и лужицких языках парадигматические соотношения объектных падежей вершины содействуют в выборе стратегии для релятивизации. Тождество винительного и именительного падежей или различие родительного и винительного облегчает опущение резумптивного местоимения, в то время как различие винительного и именительного или тождество родительного и винительного падежей требует использования декумуляционной стратегии.

Выбор стратегии также обусловлен социолингвистическими причинами. Хотя применение относительной частицы во многих случаях становится возможным только с помощью резумптивного местоимения, наличие местоимения ограничено стилистическими причинами. Присутствие местоимения больше характерно для разговорных стилей, чем для кодифицированных разновидностей языка.

В связи с этим встает вопрос, каким образом можно интерпретировать результаты. Синтаксические и социолингвистические явления можно объяснить в более широком контескте. Разговорная или даже нестандартная окраска резумптивного местоимения, как и действие фактора case matching вписывается в общеевропейские тенденции [ср. Murelli 2011]. К тому же, эффекты case matching также обнаруживаются при релятивизации других позиций.

Для интерпретации семантических критериев в наибольшей степени приемлема теория дифференцированного маркирования объектов. Неодушевленный объект является более типичным, чем одушевленный объект, в частности, чем объект, отсылающий к людям. Поэтому первые не требуют эксплицитного маркирования, тогда как последние должны получать падежный маркер в форме резумптивного местоимения. 
Трактовка морфологических факторов оказывается сложнее семантических, так как формальное отношение словоформ не выявляется в актуальном высказывании, но существует только в языковой системе, т.е. на абстрактном уровне. Возможно, здесь мы имеем дело с отражением грамматической категории одушевленности и подобных категорий, таких, как категория персональности. Они выражаются именно формальными отношениями между винительным, именительным и родительным падежами. Семантическая одушевленность/персональность при этом выражается косвенным образом. ${ }^{20}$

\section{Литература}

АГ 80 - Шведова Н. Ю. (Отв. ред.). Русская грамматика. Том II. М: Наука, 1980.

Акимова Г. Н. Тенденции в развитее относительного подчинения в современных восточногславянских языках. // Известия АН СССР, СЛЯ, 23 (2). 1964. С. 138-144.

Атрахович, К. К. (Ред.). Граматыка беларускай мовы. Том II: Сінтаксіс. Мінск: Выдав. Акадэмия навук беларускай ССР, 1966.

Виноградов В. В., Истрина Е. С. Грамматика русского языка. Том II. Синтаксис. Часть вторая. М: Изд. АН СССР, 1954.

НКРЯ = Национальный корпус русского языка. [Электронный ресурс] URL:http://www.ruscorpora.ru.

Холодилова, М.А. 2014. Относительные придаточные. // [Электронный ресурс] URL: http://rusgram.ru/Относительные_придаточные.

Bartels H., Spieß G. Restrictive Relative Clauses in the Sorbian Languages // Sprachtypologie und Universalienforschung 2012. Vol. 65 (3). P. 221-245.

Bošković Ž. On Relativization Strategies and Resumptive Pronouns. // Studies in Formal Slavic Phonology, Morphology, Syntax, Semantics and Information Structure. Proceedings of FDSL 7, Leipzig 2007/ ed. by G. Zybatow et al. Frankfurt am Main et al., Lang, 2009. P. 79-91.

Bužarovska E. Restrictive Relative Clauses in Standard Macedonian and Standard Bulgarian. // Investigations in the Bulgarian and Macedonian Nominal Expression/ ed. by M. Dimitrova-Vulchanova and O. Mišeska-Tomić. Trondheim: Tapir Akad. Forlag, 2009. pp. 230-260

Comrie B., Keenan E.L. Noun Phrase Accessibility Revisited // Language 1979. Vol. 55 (3), pp. 649-664.

Danylenko A. On the Relativization Strategies in East Slavic // Grammaticalization and Lexicalization in the Slavic Languages: Proceedings from the 36th Meeting of the Commission on the Grammatical Structure of the Slavic Languages of the International

${ }^{20}$ В случае словацкого языка возможно было бы еще одно объяснение, согласно которому это явление является косвенным влиянием синкретизма именительного и винительного падежей в парадигмах склоняемых омонимов относительной частицы (вопросительное и относительное местоимения). Но такой подход не действует в случае луж. kiž и kenž, поскольку они не имеют никаких омонимов. 
Committee of Slavists/ ed. by M. Nomachi, A. Danylenko and P. Piper: München et al.: Sagner, 2014, pp. 183-204.

Darovec M. Vzt’ažné vety v slovenčine // Studia Acadamica Slovaca 1985. Vol. 14, pp. 107-131.

Fried M. Accusative Resumptive Pronoun in the Czech Relative Clauses with Absolutive Relativizer co // Korpus, gramatika, axiologie 2010. Vol. 1 (1), pp. 16-29.

Guz W. Wh-pronoun and Complementizer Relative Clauses: Unintegration Features in Conversational Polish // Studies in Polish Linguistics 2017. Vol. 12 (1), pp. 1-26.

Keenan E.L., Comrie B. Noun Phrase Accessibility and Universal Grammar // Linguistic Inquiry 1977. 8 (1), pp. 63-99.

Kordić S. Der Relativsatz im Serbokroatischen. München, New Castle: Lincom, 1999.

Krapova I. Bulgarian Relative and Factive Clauses with an Invariant Complementizer // Lingua 2010. Vol. 120 (5). pp. 1240-1272.

Kurzová H. Der Relativsatz in den indoeuropäischen Sprachen. Hamburg: Helmut Buske, 1981.

Mendoza I. Relative Particles and Resumptive Pronouns in Slavic // Zeitschrift für Slavische Philologie 2019. Vol. 75 (1), pp. 5-42.

Murelli A. Relative Constructions in European Non-standard Varieties. Berlin, Boston: De Gruyter Mouton, 2011.

Polański K. Składnia zdania złożonego w języku górnołużyckim. Wrocław et al.: Ossolineum, 1967.

Topolińska Z. Składnia grupy imiennej // Gramatyka współczesnego jezyka polskiego. Składnia/ ed. by Z. Topolińska,. Warszawa: PWN, 1984, pp. 301-386.

Rudin C. Aspects of Bulgarian Syntax. Complementizers and WH Constructions. Bloomington (Ind.): Slavica Publishers, 2013.

Shagal Ks. 2016. Factors Regulating Variation in Macedonian Relative Clauses // In Search of the Center and Periphery. Linguistic Attitudes, Minorities, and Landscapes in the Central Balkans/ ed. by M. Makartsev and M. Wahlström. Helsinki: University of Helsinki, Department of Modern Languages, 2016, pp. 163-177.

\author{
Imke Mendoza \\ Universität Salzburg \\ (Salzburg, Austria) \\ imke.mendoza@sbg.ac.at
}

\title{
ON THE RELATIVIZATION OF OBJECTS IN SLAVIC LANGUAGES
}

This article analyzes the use of different strategies including invariant relative particles (Ru. čto, Po. co etc.) in clauses relativizing direct objects. According to the Accessibility Hierarchy proposed by Keenan and Comrie (1977), the position of the direct object does not show much internal differentiation. However, a closer look reveals a rather 
complicated variation between the "bare" relative particle and the so-called decumulation strategy (relative particle with resumptive pronoun). The choice of strategy depends on a number of factors such as (semantic) animacy, case matching and the paradigmatic relations between the case forms of the head of the relative clause. The paper suggests that these factors be interpreted both within the framework of differential object marking and through the grammatical category of animacy.

Keywords: syntax, relative clause, object marking

\section{References}

AG 80 - Shvedova N.Yu. (ed.). Russkaya grammatika. Vol. II. Moscow, «Nauka» Publ., 1980. (in Russ.)

Akimova G.N. Tendencii $v$ razvitee otnositel'nogo podchineniya $v$ sovremenny' $\mathrm{x}$ vostochnogslavyanskix yazy`kax. Izvestiya AN SSSR, SLYa, 1964, 23 (2), pp. 138-144. (in Russ.)

Atraxovich K.K. (ed.). Gramatyka belaruskaj movy. Vol. II: Sintaksis. Minsk, Vydav. Akademiya navuk belaruskaj SSR, 1966. (in Beloruss.)

Bartels H., Spieß G. Restrictive Relative Clauses in the Sorbian Languages. Sprachtypologie und Universalienforschung, 2012, vol. 65 (3), pp. 221-245.

Bošković Ž. On Relativization Strategies and Resumptive Pronouns. Studies in Formal Slavic Phonology, Morphology, Syntax, Semantics and Information Structure. Proceedings of FDSL 7, Leipzig 2007, ed. by G. Zybatow et al. Frankfurt am Main et al., Lang, 2009, pp. 79-91.

Bužarovska E. Restrictive Relative Clauses in Standard Macedonian and Standard Bulgarian. Investigations in the Bulgarian and Macedonian Nominal Expression, ed. by M. Dimitrova-Vulchanova and O. Mišeska-Tomić. Trondheim: Tapir Akad. Forlag, 2009, pp. 230-260.

Comrie B., Keenan E.L. Noun Phrase Accessibility Revisited. Language, 1979, vol. 55 (3), pp. 649-664.

Danylenko A. On the Relativization Strategies in East Slavic. Grammaticalization and Lexicalization in the Slavic Languages: Proceedings from the 36th Meeting of the Commission on the Grammatical Structure of the Slavic Languages of the International Committee of Slavists, ed. by M. Nomachi, A. Danylenko and P. Piper. München et al.: Sagner, 2014, pp. 183-204.

Darovec M. Vzt'ažné vety v slovenčine. Studia Acadamica Slovaca, 1985, vol. 14, pp. 107-131. (in Slov.)

Fried M. Accusative Resumptive Pronoun in the Czech Relative Clauses with Absolutive Relativizer co. Korpus, gramatika, axiologie, 2010, vol. 1 (1), pp. 16-29.

Guz W. Wh-pronoun and Complementizer Relative Clauses: Unintegration Features in Conversational Polish. Studies in Polish Linguistics, 2017, vol. 12 (1), pp. 1-26.

Keenan E. L., Comrie B. Noun Phrase Accessibility and Universal Grammar. Linguistic Inquiry, 1977, 8 (1), pp. 63-99. 
Kholodilova M. A. Otnositel'nye pridatochnye (2014). [E`lektronny $\mathrm{j}$ resurs] URL: http://rusgram.ru/Otnositel'ny`e pridatochny`e. (in Russ.)

Kordić S. Der Relativsatz im Serbokroatischen. München, New Castle: Lincom, 1999. (in German)

Krapova I. Bulgarian Relative and Factive Clauses with an Invariant Complementizer. Lingua, 2010, vol. 120 (5), pp. 1240-1272.

Kurzová H. Der Relativsatz in den indoeuropäischen Sprachen. Hamburg: Helmut Buske, 1981. (in German)

Mendoza I. Relative Particles and Resumptive Pronouns in Slavic. Zeitschrift für Slavische Philologie, 2019, vol. 75 (1), pp. 5-42.

Murelli A. Relative Constructions in European Non-standard Varieties. Berlin, Boston: De Gruyter Mouton, 2011.

NKRYa = Nacional'nyj korpus russkogo yazyka. [E`lektronny`j resurs]. URL: http:// www.ruscorpora.ru. (in Russ.)

Polański K. Składnia zdania złożonego w języku górnołużyckim. Wrocław et al.: Ossolineum, 1967. (in Polish)

Rudin C. Aspects of Bulgarian Syntax. Complementizers and WH Constructions. Bloomington (Ind.): Slavica Publishers, 2013.

Shagal Ks. Factors Regulating Variation in Macedonian Relative Clauses. In Search of the Center and Periphery. Linguistic Attitudes, Minorities, and Landscapes in the Central Balkans, ed. by M. Makartsev and M. Wahlström. Helsinki: University of Helsinki, Department of Modern Languages, 2016, pp. 163-177.

Topolińska Z. Składnia grupy imiennej. Gramatyka wspótczesnego jezyka polskiego. Sktadnia, ed. by Z. Topolińska. Warszawa: PWN, 1984, pp. 301-386. (in Polish)

Vinogradov V.V., Istrina E.S. Grammatika russkogo yazyka. Vol. II. Sintaksis. Chast' vtoraya. Moscow, Izd. AN SSSR, 1954. (in Russ.) 